\title{
Internally consistent geothermobarometers for garnet harzburgites
}

Girnis, A.V. ${ }^{1,2}$, Stachel, T. ${ }^{2}$, Brey, G.P. ${ }^{2}$. Harris, J. ${ }^{3}$, Philips D. ${ }^{4}$

1. Institute for the Geology of Ore Deposits (IGEM), 35 Staromonetny, Moscow 109017, Russia

2. Institut für Mineralogie, Universität Frankfurt, Senckenberganlage 28, D-60054 Frankfurt, Germany

3. Department of Geology \& Applied Geology, University of Glasgow, Glasgow G12 8QQ, Scotland. UK

4. Anglo American Research Laboratories (Pty) Ltd., P.O. Box 106, Crown Mines, 2025, South Africa

Geothermobarometry of garnet harzburgites and harzburgitic inclusions in diamonds is restricted to the use of three thermometers (Fe-Mg exchange between Ol-Grt, Opx-Grt and Ol-Sp) with all their pit falls and to one barometer (Al-content of Opx coexisting with Grt). Trace element thermobarometers are calibrated against these experimentally derived thermobarometers. Garnet and spinel bearing parageneses offer further possibilities (Doroshev et al. 1997, Brey et al. and Girnis \& Brey, Part I and II, accepted for publication by European Journal of Mineralogy) which allow pressure and temperature estimates from a combination of any two of the four harzburgitic phases. The latter authors presented experimental results and a thermodynamic model for coexisting olivine, orthopyroxene, spinel and garnet in the system $\mathrm{FeO}-\mathrm{MgO}-\mathrm{Al}_{2} \mathrm{O}_{3}-\mathrm{SiO}_{2}-\mathrm{Cr}_{2} \mathrm{O}_{3}$ (FMASCr). For application to natural rocks this model needs refinement which may be obtained from the use of mineral compositions from well equilibrated natural samples.

Seven independent reactions may be considered in the FMASCr system which are described by seven equations for equilibrium: $\Delta_{r} G^{i}=R T \ln K_{i}+\Delta_{r} G_{0}{ }^{i}+\Delta_{r} G_{e x}{ }^{i}=0, \quad i=1,2, \ldots 7$.

\begin{tabular}{|l|l|}
\hline 1. Fe-Mg exchange olivine-spinel & 4. $\mathrm{Cr}-\mathrm{Al}$ exchange orthopyroxene-spinel \\
2. Fe-Mg exchange olivine-orthopyroxene & 5. $\mathrm{Cr}$ - $\mathrm{Al}$ exchange garnet-spinel \\
3. Fe-Mg exchange olivine-garnet & $\begin{array}{l}\text { 6. } \mathrm{MgSiO}_{3}+\mathrm{MgAlAlSiO}_{6}=\mathrm{Mg}_{3} \mathrm{Al}_{2} \mathrm{Si}_{3} \mathrm{O}_{12} \\
\text { 7. } \mathrm{MgSiO}_{3}+\mathrm{MgAl}_{2} \mathrm{O}_{4}=\mathrm{Mg}_{2} \mathrm{SiO}_{4}+\mathrm{Mg}_{3} \mathrm{Al}_{2} \mathrm{Si}_{3} \mathrm{O}_{12}\end{array}$ \\
\hline
\end{tabular}

For known compositions of all the phases from a four mineral harzburgitic assemblage, the intersection of any two independent reactions defines equilibrium temperature and pressure. The remaining five reactions define five pressure and temperature independent constraints on the composition of the phases. These constraints may be compared with mineral compositions from natural garnet-spinel harzburgites to refine the thermodynamic parameters of equilibria 1-7. Fully equilibrated xenoliths are rare, especially those with high $\mathrm{Cr}$ and low $\mathrm{Ca}$ garnets and very low $\mathrm{Ca}$ orthopyroxenes. As inclusions in diamonds, however, such depleted parageneses are common, whereby touching minerals are best suited for our modelling. They were able to continuously adjust to changing physical conditions and most likely represent equilibrium assemblages. Non-touching mineral inclusions should reflect growth conditions of diamonds but may be disequilibrium assemblages because of successive incorporation into diamond from a chemically changing environment. For the refinement we used the world-wide inclusion database of Stachel and Harris (1997) plus the De Beers Pool Mines data of Phillips and Harris (1995).

From the comparison of the measured and calculated mineral compositions systematic errors in the thermodynamic parameters of our original model from the FMASCr system will become apparent. By first using the data set of touching parageneses only we found good reproduction of the composition of all phases except for $\mathrm{Al}$ and $\mathrm{Cr}$ in orthopyroxene. We then adjusted our model accordingly within the constraints of the experimental brackets and obtained our thermodynamic Model I. The temperature range calculated for touching minerals is restricted to $1000-1200^{\circ} \mathrm{C}$. Application of the Model I parameters to the whole set of mineral compositions results in high 
temperatures for many of the non-touching inclusions (more than $1600^{\circ} \mathrm{C}$ ) and higher discrepancy with respect to $\mathrm{Al}$ in orthopyroxene. Here, disequilibrium will play a role to some extent. It should not be the case for the majority of the inclusions, since, at the low temperature end, touching and non-touching inclusions overlap completely and discrepancies arise only at higher temperatures suggesting an error in the temperature dependence of some thermodynamic parameters. Thus we derived thermodynamic Model II with the complete inclusion database.

Both models are compatible with the experimental data (Part I, II) and the thermodynamic database of Berman (1988) and Sack \& Ghiorso (1994). We have no sound reason to choose one of the two models as the best one to use in thermobarometry. The two models yield extreme values of pressure and temperature, the difference being a measure of the error in $\mathrm{P}, \mathrm{T}$ estimates.

Here, we want to point out specifically that the $\mathrm{Cr}-\mathrm{Al}$ exchange reactions between garnet and spinel and orthopyroxene and spinel are much more temperature-sensitive than the respective $\mathrm{Fe}-\mathrm{Mg}$ exchange equilibria. The expressions for such $\mathrm{Cr}-\mathrm{Al}$ exchange geothermometers derived from our results are as follows ( $\mathrm{T}$ in $\mathrm{K}, \mathrm{P}$ in bar):

$$
\begin{aligned}
\mathbf{T}= & {\left[5584-541 X_{F e}^{O p x}-2406\left(3 C r^{O p x}-A l^{O p x}\right)+675 X_{M g}^{M 1.0 p x}+878 X_{F e}^{M 1 . O p x}+1224 X_{F e}^{S p}+\right.} \\
& \left.1949 X_{C r}^{S_{p}}\left(1.41-X_{C r}^{S p}\right)+0.00192 P\right] /\left(4.456+\ln K_{4}-0.233 X_{F e}^{S p}\right)
\end{aligned}
$$

and

$$
\mathbf{T}=\frac{6036-1746.4 X_{F e}^{G r t}-2194 X_{C a}^{G r t}+950 X_{C r}^{G r t}+1224 X_{F e}^{S p}+1949 X_{C r}^{S p}\left(1.41-X_{C r}^{S p}\right)+0.0058 P}{2.535+\ln K_{5}-0.233 X_{F e}^{S p}}
$$

where $K_{4}=\frac{X_{A l}^{M 1 . O p x} X_{C r}^{S p}}{X_{C r}^{M 1, O p x} X_{A l}^{S p}}, K_{5}=\frac{X_{A l}^{G r t} X_{C r}^{S p}}{X_{C r}^{G r} X_{A l}^{S p}}$ and $\mathrm{Al}^{\mathrm{Opx}}, \mathrm{Cr}^{\mathrm{Opx}}=\mathrm{Al}, \mathrm{Cr}$ in the structural formula of opx

For a four-phase association the seven equations may be used to determine pressure and temperature which means calculation of the intersections of the different reactions and averaging the intersection parameters. As for inclusions in diamonds, the general case is that not all four phases are present and the composition of missing phases must be calculated along with pressure and temperature with an approach similar to that of Kawasaki (1987). This leads to a larger uncertainty in calculated pressure and temperature.

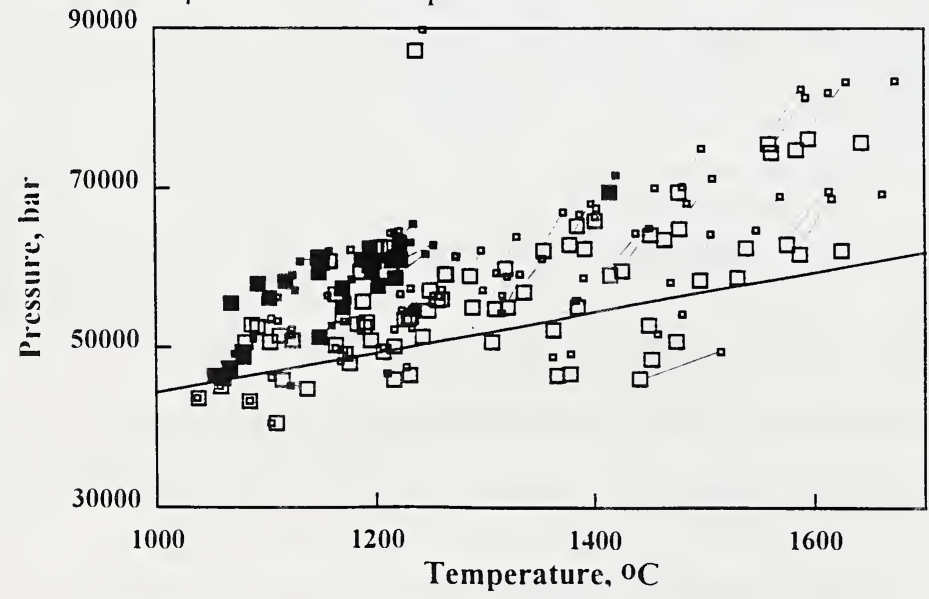

Fig. 1: Pressure and temperature calculated for inclusions in diamonds using the method given in this work. Large and small squares connected with lines show values obtained for Models I and II, respectively. Solid symbols are for touching inclusions (mainly orthopyroxenegarnet).

Application of the described method to inclusions in diamonds is shown in Fig. 1. The equilibrium temperatures for touching inclusions range from 1000 to $1200^{\circ} \mathrm{C}$ at pressures from 45 to 
65 kbar. All samples plot in the diamond stability field and close to a cratonic geotherm. Temperatures for the non-touching iclusions range up to $1600{ }^{\circ} \mathrm{C}$ in the same pressure interval. Keeping in mind that not all inclusions represent equilibrium assemblages we interpret the temperatures calculated for non-touching inclusions as indicative for diamond growth over a wide range of temperatures off cratonic geothermal gradients. Touching minerals may record diamond growth conditions along geothermal gradients or subsequent cooling to conditions of a steady state geotherm. We also find that $\mathrm{Cr} /(\mathrm{Cr}+\mathrm{Al})$ of garnet does not correlate strongly with pressure and that the most chromian garnets form at pressures lower than $60 \mathrm{kbar}$ in equilibrium with spinel (Fig. 2). Absence of highly chromian garnets at higher pressures indicates spinel-free mantle parageneses controlled by bulk compositional constraints. Very high $\mathrm{Cr}$ in some garnets indicates locally high $\mathrm{Cr} / \mathrm{Al}$ ratios in the mantle but not extremely high pressures. In a spinel-free association increasing pressure causes a decrease of $\mathrm{Cr}$ in garnet because of increasing modal abundance.

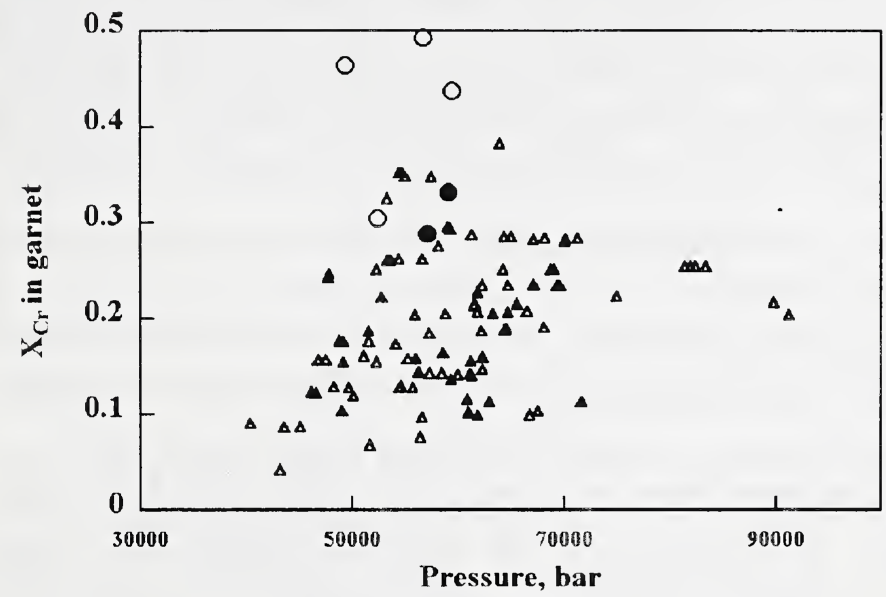

Fig. 2: $\mathrm{Cr} /(\mathrm{Cr}+\mathrm{Al})$ ratio of garnet inclusions as function of pressure calculated with Model II. Solid triangles represent garnets touching with orthopyroxene and solid circles touching with orthopyroxene + spinel.

\section{References}

Bermann, R.G., 1988, Internally-consistent thermodynamic data for minerals in the system $\mathrm{Na}_{2} \mathrm{O}$ $\mathrm{K}_{2} \mathrm{O}-\mathrm{CaO}-\mathrm{MgO}-\mathrm{FeO}-\mathrm{Fe}_{2} \mathrm{O}_{3}-\mathrm{Al}_{2} \mathrm{O}_{3}-\mathrm{SiO}_{2}-\mathrm{H}_{2} \mathrm{O}-\mathrm{CO}_{2}$ : J. Petrol., v. 29, p. 445-522

Brey, G.P., Doroshev, A.M., Girnis, A.V., and Turkin, A.I., Garnet-spinel-olivine-orthopyroxene equilibria in the $\mathrm{FeO}-\mathrm{MgO}-\mathrm{Al}_{2} \mathrm{O}_{3}-\mathrm{SiO}_{2}-\mathrm{Cr}_{2} \mathrm{O}_{3}$ system: $\mathrm{I}$. Composition and molar volumes of minerals: Accepted Eur. J. Mineral.

Doroshev, A.M., Brey, G.P., Girnis, A.V., Turkin, A.I. and Kogarko, L.N., 1997, Pyropeknorringite garnets in the Earth's mantle: experiments in the $\mathrm{MgO}-\mathrm{Al}_{2} \mathrm{O}_{3}-\mathrm{SiO}_{2}-\mathrm{Cr}_{2} \mathrm{O}_{3}$ system: Russian Geology and Geophysics, v. 38, n. 2, p. 559-586.

Girnis, A.V. and Brey, G.P., Garnet-spinel-olivine-orthopyroxene equilibria in the $\mathrm{FeO}-\mathrm{MgO}-\mathrm{Al}_{2} \mathrm{O}_{3}$ $\mathrm{SiO}_{2}-\mathrm{Cr}_{2} \mathrm{O}_{3}$ system: II. Thermodynamic analysis: Accepted Eur. J. Mineral.

Phillips, D. and Harris, J.W., 1995, Geothermobarometry of diamond inclusions from the De Beers Pool Mines, Kimberley, South Africa: $6^{\text {th }}$ IKC, Extended Abstracts, p. 441-443.

Sack, R.O. and Ghiorso, M.S., 1994, Thermodynamics of multicomponent pyroxenes: III. Calibration of $\left.\mathrm{Fe}^{2+(} \mathrm{Mg}\right)_{-1}, \mathrm{TiAl}_{2}\left(\mathrm{MgSi}_{2}\right)_{-1}, \mathrm{TiFe}^{3+}\left(\mathrm{MgSi}_{2}\right)_{-1}, \mathrm{NaAl}(\mathrm{CaMg})_{-1}, \mathrm{Al}_{2}(\mathrm{MgSi})_{-1}$ and $\mathrm{Ca}(\mathrm{Mg})_{-1}$ exchange reactions between pyroxenes and silicate melts: Contrib. Mineral. Petrol., v. 118, p. 271296

Stachel, T. and Harris, J.W., 1997, Syngenetic inclusions in diamond from the Birim field (Ghana) - a deep peridotitic profile with a history of depletion and re-enrichment: Contrib. Mineral. Petrol., v. 127 , p. $336-352$. 